University of Nebraska - Lincoln

DigitalCommons@University of Nebraska - Lincoln

10-2007

\title{
Gregarina niphandrodes (Eugregarinorida: Septatorina): Oocyst Surface Architecture
}

John J. Janovy Jr.

University of Nebraska - Lincoln, jjanovy1@unl.edu

Matthew G. Bolek

Oklahoma State University, bolek@okstate.edu

Jillian Tikka Detwiler

Purdue University, jdetwile@purdue.edu

Samana Schwank

London School of Tropical Medicine, Samana.Schwank@lshtm.ac.uk

Alaine Knipes

University of Nebraska - Lincoln, lainey244@yahoo.com

See next page for additional authors

Follow this and additional works at: https://digitalcommons.unl.edu/bioscijanovy

Part of the Parasitology Commons

Janovy, John J. Jr.; Bolek, Matthew G.; Detwiler, Jillian Tikka; Schwank, Samana; Knipes, Alaine; and Langford, Gabriel J., "Gregarina niphandrodes (Eugregarinorida: Septatorina): Oocyst Surface Architecture" (2007). John Janovy Publications. 57.

https://digitalcommons.unl.edu/bioscijanovy/57

This Article is brought to you for free and open access by the Papers in the Biological Sciences at DigitalCommons@University of Nebraska - Lincoln. It has been accepted for inclusion in John Janovy Publications by an authorized administrator of DigitalCommons@University of Nebraska - Lincoln. 


\section{Authors}

John J. Janovy Jr., Matthew G. Bolek, Jillian Tikka Detwiler, Samana Schwank, Alaine Knipes, and Gabriel J. Langford 
Janovy, Bolek, Detwiler, Schwank, Knipes \& Langford in Journal of Parasitology 93 (2007)

Copyright 2007, American Society of Parasitologists. Used by permission.

J. Parasitol., 93(3), 2007, pp. 714-716

\section{Gregarina niphandrodes (Eugregarinorida: Septatorina): Oocyst Surface Architecture}

J. Janovy, Jr., M. G. Bolek, J. Detwiler, S. Schwank, A. Knipes, and G. J. Langford, School of Biological Sciences, University of NebraskaLincoln, Lincoln, Nebraska68588-0118.e-mail: jjanovy1@unl.edu

ABSTRACT: The surface architecture of oocysts produced by Gregarina niphandrodes (Eugregarinorida) from Tenebrio molitor adults (Coleoptera: Tenebrionidae) as revealed by scanning electron microscopy is reported. Gametocysts were allowed to dehisce on $15-\mathrm{mm}$, round cover glasses; the cover glasses with their oocysts chains were then mounted on stubs without further processing, and sputter-coated with $20-\mathrm{nm}$ gold-palladium. Scanning electron microscopy was performed at 10$15 \mathrm{kV}$ with a Hitachi 3000N SEM. Oocysts retained their characteristic shapes as reported in the original species description but showed longitudinal ridges of relatively uniform height, width, and spacing, in separate fields on either side of a central equatorial bulge in the oocysts. There was no ultrastructural evidence of an enclosing external sheath holding the oocysts in a chain. Oocyst ends were flared slightly, and the chain itself was twisted, with adjacent oocysts offset slightly from one another. This article now provides an additional set of structural characters potentially useful in gregarine systematics.

The class Gregarinasina (Apicomplexa) is perhaps the most diverse eukaryotic taxon because its members parasitize invertebrates, especially annelids and arthropods, although gregarine species have been described from most invertebrate phyla. Descriptive work, however, is somewhat hindered by a number of factors, such as gregarines' lack of medical importance, their seeming paucity of structural features, and the fact that so many potential hosts in interesting parts of the world are relatively inaccessible to workers because of logistical constraints, political turmoil, and lack of funds. Nevertheless, in recent years, Clopton and various coworkers have established criteria by which new taxa should be described and have standardized terminology for shapes and proportions (Clopton et al., 1991, 1992; Clopton, 2004; Clopton et al., 2004). This body of published work shows clearly that oocyst shape and size are highly stable characters of major taxonomic importance.

The present study was intended to increase the number of characters available for gregarine systematics by examining surface architecture of oocysts using scanning electron microscopy. Gregarina niphandrodes Clopton, Percival, and Janovy, 1991, from adult Tenebrio molitor (Coleoptera: Tenebrionidae) was chosen as the material because both host and parasite are common, well-studied species, and adult beetles are generally infected with only this single gregarine species (Clopton et al., 1992). In addition, G. niphandrodes gametocysts are relatively large and easily handled, and oocyst production ("sporogeny") is easily achieved in moist chambers (Clopton and Janovy, 1993).

Insects used in this study were from cultures maintained for many years at the University of Nebraska-Lincoln using wheat bran and potatoes as food. These are the same cultures from which the type hosts 


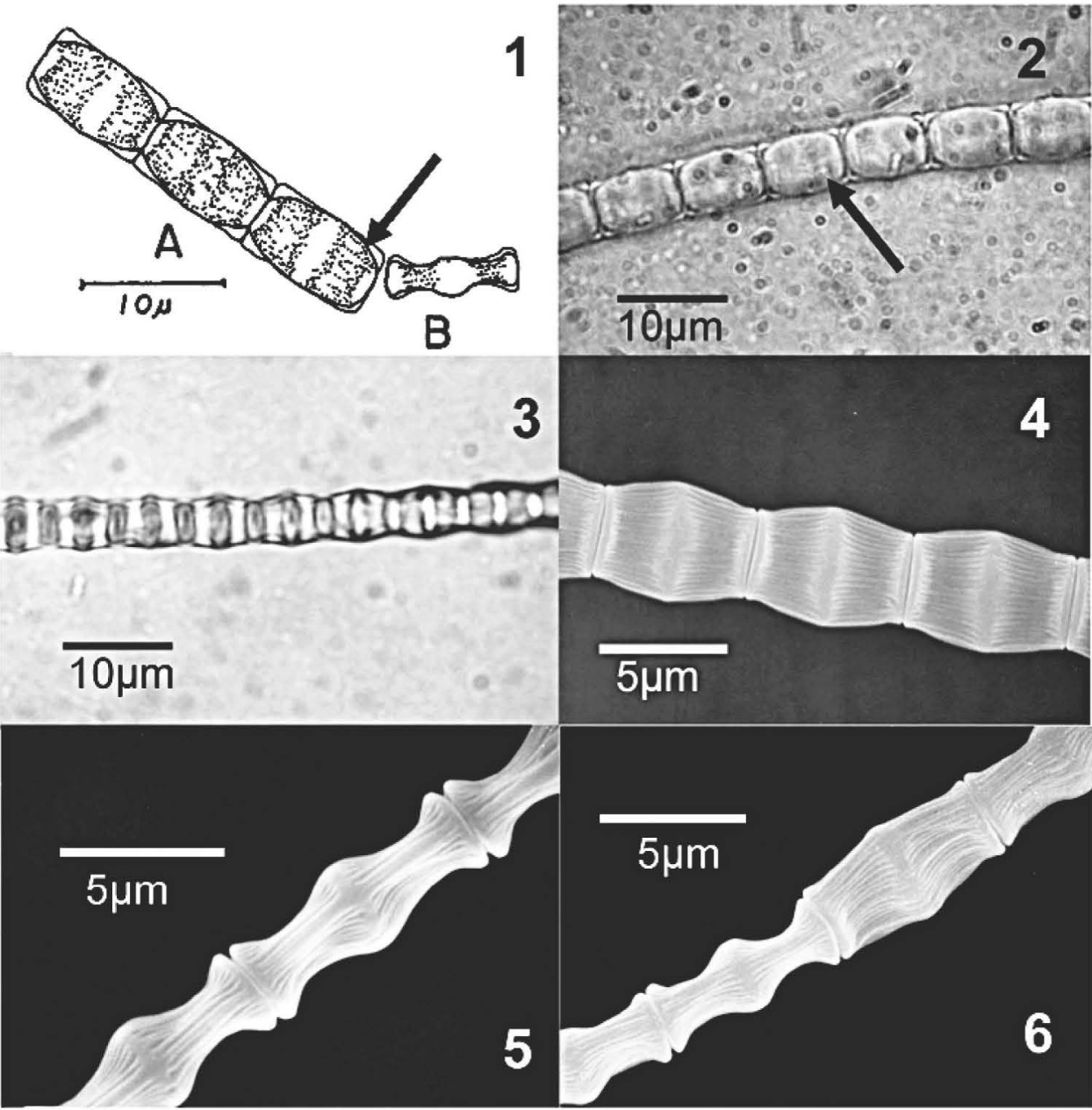

FIGURES 1-6. (1) Drawing of Gregarina niphandrodes oocysts from the original species description (Clopton et al., 1991) showing characteristic morphology as seen in 1:1 glycerin:water suspensions. Arrow points to patterns that can now be interpreted as longitudinal ridges. (2) Bright-field light micrograph of a G. niphandrodes oocyst chain suspended in 1:1 glycerin:water. Arrow points to an area that can now be interpreted as showing longitudinal ridges. (3) Bright-field light micrograph of the same G. niphandrodes oocyst chain shown in Figure 2, but taken before submersion in glycerin:water. (4-6) Scanning electron micrographs of $G$. niphandrodes oocysts, showing surface ridges and the nature of joints between oocysts.

and parasite type specimens were taken (Clopton et al., 1991). Gametocysts were harvested by isolating adult beetles overnight in a plastic shoebox with a slightly moistened paper towel. Shed gametocysts were picked up with a fine camel hair brush and transferred to $1 \%$ neutral buffered formalin to be washed for a few minutes before isolation for dehiscence. Gametocysts were placed on 15-mm-diameter, circular cover glasses coated with poly-L-lysine (Sigma, St. Louis, Missouri) according to package instructions and placed in the center well of covered Falcon plastic organ-culture dishes with water in the moat; dehiscence occurred within 3 days. Oocysts were prepared for scanning electron microscopy by simply attaching the cover glass, with its oocyst chains, to a stub then sputter-coating the specimen with 200 -nm gold-palladium using a Technics Hummer II sputterer. Scanning electron microscopy was performed at $10-15 \mathrm{kV}$ with a Hitachi $3000 \mathrm{~N}$ SEM.

Oocysts also were prepared for light microscopy by placing oocyst chains dry on a slide and covering them with a $22 \times 22 \mathrm{~mm}$ No. 1 cover glass, tacked down at the corners with Elmer's glue. This kind of preparation allowed photographs to be taken of oocysts under oil immersion but as they occur "naturally," i.e., in air. The same oocysts chain could then be photographed after flooding with 1:1 glycerin:water as was done in the original description (Clopton et al., 1991). Digital photographs were taken with a Nikon Coolpix 995 camera fitted with an Optem 25-70-14 adapter (www.optemintl.com). Photographs were converted to grayscale, and brightness and contrast were adjusted slight- ly using Adobe Photoshop 6.0. The plate of figures was assembled using Adobe Illustrator 10

Figure 1 is from the original species description and is a drawing of oocysts suspended in 1:1 glycerin:water. In this kind of preparation, oocysts can move freely, so they can be seen in various profiles. Under these conditions, G. niphandrodes oocysts are remarkably uniform in size and shape, with a raised center portion and flared ends as seen from the side, and an oblong, almost rectangular shape but with rounded corners and an apparent sheath holding the chain together (Fig. 2). At the same magnification, but without flooding (Fig. 3), the raised equatorial portion is evident, and the oocysts have a truncated diamond shape when viewed "from above," that is, so that maximum length and width were apparent. There is no evidence that sputter-coating and photographing the oocysts without prior use of standard SEM preparation techniques (glutaraldehyde and osmium fixation, dehydration, critical point drying) altered overall shape. The profile as seen from the side is well preserved in the SEM specimens (Figs. 5, 6); additional features not obvious at the light level are the regularly spaced longitudinal ridges of almost uniform height, width, and spacing on either side of the central raised area. However, the original description drawings hint at these ridges (Fig. 1, labeled $4 \mathrm{~A}$ in the original description), and they can be seen, although not clearly, in the glycerin preparations (Figs. 1, 2, arrows). Immersion in glycerin:water evidently makes a sheath of some kind visible, perhaps by swelling it, thus giving the oocysts a more 
Janovy, Bolek, Detwiler, Schwank, Knipes \& Langford in Journal of Parasitology 93 (2007)

Copyright 2007, American Society of Parasitologists. Used by permission.

rectangular appearance then when dry (cf. Figs. 1, 2 vs. Fig. 3). The broad, truncated diamond shape seen in dry oocysts is also clearly seen in the SEMs (Figs. 3, 4). There was no ultrastructural evidence of an enclosing external sheath holding the oocysts in a chain. Oocyst ends were flared slightly, and the chain itself was twisted with adjacent oocysts offset slightly from one another.

There are 2 main contributions of this study. First, the demonstration that oocyst structure as seen under the light microscope is preserved through sputter-coating and scanning electron microscopy, even though standard fixation, dehydration, and critical-point drying are not performed on the specimens. Second, there are distinct, fine folds or ridges, arranged in a distinctive pattern, on the oocysts. Although these structural features are potentially useful in future gregarine systematic work, such use requires comparative information on oocyst surface architecture from a variety of gregarine taxa.

The differences between oocyst structure as seen in glycerin:water suspensions versus in air at oil immersion magnifications could be the result of refraction of the light beam, although there is also a possibility that the cysts are contained within a sheath of some kind that is expanded in glycerin:water. These differences also emphasize the importance of reporting oocyst preparation methods in detail, for example, as exemplified by Clopton et al. (2004), when using such measurements in taxonomic studies.
The authors wish to thank Kit Lee for assistance with the scanning electron microscopy.

\section{LITERATURE CITED}

Clopton, R. E. 2004. Standard nomenclature and metrics of plane shapes for use in gregarine taxonomy. Comparative Parasitology 71: $130-140$.

-, T. J. CoOK, AND J. L. CooK. 2004. Naiadocystis phykoterion n. gen., n. sp. (Apicomplexa: Eugregarinida: Hirmocystidae), from the Mexican pygmy grasshopper, Paratettix mexicanus (Orthoptera: Tetrigidae), in the Texas Big Thicket with recognition of three previously described species of Naiadocystis. Journal of Parasitology 90: 301-307.

, AND J. JANOVY JR. 1993. Developmental niche structure in the gregarine assemblage parasitizing Tenebrio molitor. Journal of Parasitology 79: 701-709.

-, AND T. J. PERCIVAL 1992. Host stadium specificity in the gregarine assemblage parasitizing Tenebrio molitor. Journal of Parasitology 78: 334-337.

, T. J. Percival, AND J. JAnovy JR. 1991. Gregarina niphandrodes n. sp. (Apicomplexa: Eugregarinorida) from adult Tenebrio molitor (L.) with oocyst descriptions of other gregarine parasites of the yellow mealworm. Journal of Protozoology 38: 472-479. 